\title{
Revisiting bronchoscopic intratumoral chemotherapy in malignant central airway obstruction via EUS-B approach and its review of literature
}

\author{
Ram Niwas ${ }^{1}$, Gopal Chawla ${ }^{1}$, Puneet Pareek ${ }^{2}$, Nishant Kumar Chauhan ${ }^{1}$, Naveen Dutt ${ }^{1}$ \\ ${ }^{1}$ Department of Pulmonary Medicine; ${ }^{2}$ Department of Radiotherapy, All India Institute of Medical Sciences, Jodhpur, \\ India
}

\begin{abstract}
Critical central airway obstruction has always been a dreaded complication to which interventional pulmonologist commonly encounters. There have been various modalities which are used for the management and palliation, which includes mechanical coring, laser, cryoextraction, electrocautery and airway stenting. Rigid bronchoscopy with or without jet ventilation has been corner stone of therapeutics and palliation of central airway obstruction. There are only a few conditions where it is not possible to use rigid bronchoscopy. Here we report a case of metastatic tracheal tumour which presented with critical airway obstruction in a
\end{abstract}

Correspondence: Dr Ram Niwas, Department of Pulmonary Medicine, All India Institute of Medical Sciences, Jodhpur 342005, India. Tel. +91.9999493179.

E-mail: rniwasaiims@gmail.com

Key words: Tracheal tumour; intralesional chemotherapy; atlantoaxial subluxation; EUS-B.

Conflict of interest: The authors declare no conflict of interest.

Contributions: RN, GC, PP, NKC, concept and design; RN, GC, PP, $\mathrm{NKC}, \mathrm{ND}$, definition of intellectual content; RN, GC, literature search; GC, experimental studies and data analysis; GC, ND, data acquisition; RN, GC, manuscript preparation; RN, GC, PP, NKC, manuscript review; RN, guarantor.

Ethics approval: Treatment options were approved by the Institution Review Board.

Availability of data and materials: All data underlying the findings are fully available.

Patient consent for publication: The patient provided informed consent for publication of the case.

Received for publication: 17 April 2020.

Accepted for publication: 3 August 2020.

CCopyright: the Author(s), 2020

Licensee PAGEPress, Italy

Monaldi Archives for Chest Disease 2020; 90:1324

doi: 10.4081/monaldi.2020.1324

This article is distributed under the terms of the Creative Commons Attribution Noncommercial License (by-nc 4.0) which permits any noncommercial use, distribution, and reproduction in any medium, provided the original author(s) and source are credited. patient who had atlantoaxial instability (AAI) due to rheumatoid arthritis. Here we used endobronchial ultrasound scope (EBUS) via esophageal route, i.e. EUS-B guided approach for sampling of the tracheal tumour, and intratumoral chemotherapy was instilled in multiple sessions, which resulted in shrinking of tumour, thus relieving the critical airway obstruction. This is the first report of using EUS-B approach for intratumoral chemotherapy for tracheal tumors. Bronchoscopic intratumoral chemotherapy therapy (BITC) in tracheal tumors is also one of the options but has not been explored much and there has been a dearth of literature for it.

\section{Introduction}

Malignant central airway obstruction is usually managed by multidisciplinary approach involving tumour debulking, stent placement and palliative radiotherapy (RT). Rigid bronchoscopy has been main stay for this procedure [1]. There are few conditions where rigid bronchoscopy is contraindicated or may prove counterproductive. Atlantoaxial instability is one of such cases where any manipulation of cervical spine could result in spinal cord compression [2]. In such cases BITC may be attempted via flexible bronchoscope, EBUS or EUS-B approach. EUS-B approach i.e. using endobronchial ultrasound scope (EBUS) for oesophageal ultrasound which has been used time and again, has proven to be effective and with less side effects [3]. We used this approach in our case of malignant central airway obstruction thus not comprising the airway. Later this approach was improvised for first time in available literature for intratumoral chemotherapy.

\section{Case Report}

A 53-year-old female farmer, non-smoker but with history of biomass exposure presented with cough for 4 weeks. She was diagnosed 3 years back with atlantoaxial Instability (AAI) due to rheumatoid arthritis for which she was using a semi-rigid cervical collar and was taking mycophenolate mofetil. She had cough which used to get worsened on exertion and was accompanied by noisy breathing. Patient had breathlessness which progressed from grade II to grade III in the last 3 months. Spirometry showed fixed airway obstruction with flattening of inspiratory and expiratory limb of the flow volume curve on spirometry. Chest radiology showed possibility of tracheal mass which was later confirmed on computerized tomographic scan (CT scan). CT showed soft tissue endotracheal lesion of size $15.5 \times 13.9 \times 28.1 \mathrm{~mm}$ approximately $8.8 \mathrm{~mm}$ proximal to tracheal 
bifurcation. Mass had a broad base and was arising from the right lateral and posterior wall encroaching $75 \%$ lumen resulting in critical airway obstruction. Lung window showed centrilobular and peri-bronchial nodules in bilateral lower lobes with tree in bud appearance with ground glass opacity suggestive of pneumonia (Figure 1).

Bronchoscopy revealed fleshy globular mass which had tortuous vessels over it and Karl Storz scope (C-MAC@ FIVE S) with outer diameter $3.5 \mathrm{~mm}$ could just be negotiated. Biopsy was deferred due to anticipated haemorrhage as tumour appeared very vascular. As in cases of critical airway obstruction even mild haemorrhage can asphyxiate patient as airway is already being compromised. In addition, tracheal washings were positive for acid fast bacilli. Rigid bronchoscopy is the procedure of choice for managing central airway obstruction (CAO). However, in our case it was not possible due to AAI [3]. So, TBNA was planned via EUS-B approach. EBUS scope (EVIS EXERA II, Olympus Inc., Tokyo, Japan) was introduced via oesophagus [3,4]. Sonography showed heterogenous mass with a coursing vessel and had well defined margins. It was obliterating almost $75 \%$ of lumen and was extending almost $2 \mathrm{~cm}$ longitudinally. EUS-B guided FNAC was done and three passes were taken. FNAC was suggestive of squamous cell carcinoma. PET CT showed FDG avid very small subcarinal nodes (SUV 4.2) and mesenteric nodes (SUV 4.9) along with endotracheal mass (SUV 9.6) rendering it non-operable.

In non-operable critical airway obstruction, only options are related to palliation of symptoms. Palliation of symptoms can be achieved by debulking procedures via rigid bronchoscopy (RB) or by using radiotherapy. RB was not an option as the patient was having AAI. Radiotherapy primarily was deferred as acute oedema post RT would have resulted in a catastrophe in form of asphyxia.
Systemic chemotherapy alone would have taken long time to act and patient had tuberculosis which would have become fulminant. Thus, there was need of modality that could palliate symptoms and be acceptable. Hence, intratumoral chemotherapy therapy (ITC) for palliation of CAO was considered. After informed consent, she underwent novel EUS-B guided intratumoral cisplatin instillation. Using EUS-B had advantages as critically obstructed airway was not compromised further. ITC required multiple sessions and with this approach complications such as hypoxia, aspiration pneumonia, haemorrhage and fever, which have all been seen in previous studies (Table 1), were avoided. Patient needed systemic chemotherapy as it was a metastatic disease which was started after 4 weeks of initiation of antitubercular treatment.

For EUS-B guided ITC, EBUS scope was introduced in oesophagus. After visualizing endotracheal mass via EUS-B, EBUS needle was used to puncture it and in first session $10 \mathrm{ml}$ of cisplatin in aqueous solution $(4 \mathrm{mg} / \mathrm{ml})$ was instilled into the mass in three different sites. Dose was according to previous study where they have used cisplatin intratumorally [3]. Minimal increase in size was visualised sonographically while instillation. Patient had no peri procedural and post procedural complication and check bronchoscopy after 1 week showed around $10 \%$ decrease in size. Sessions of ITC were repeated at week 2, 3 and 4. In the $3^{\text {rd }}$ and $4^{\text {th }}$ week we used cisplatin $40 \mathrm{mg}(4 \mathrm{mg} / \mathrm{ml})$ in combination with gemcitabine $500 \mathrm{mg}(100 \mathrm{mg} / \mathrm{ml})$ as mass had shrunken in size and there was scope of instilling more volume of drug. After 4 weeks of anti-tubercular treatment patient was started on systemic chemotherapy. There was almost $50 \%$ reduction at $4^{\text {th }}$ week. Check FOB after 6 months showed that CAO reduced to almost $25 \%$ (Figure 2). Follow-up CT scan was planned but could not be done as patient expired due to sudden cardiac arrest, a year after the initial procedure.
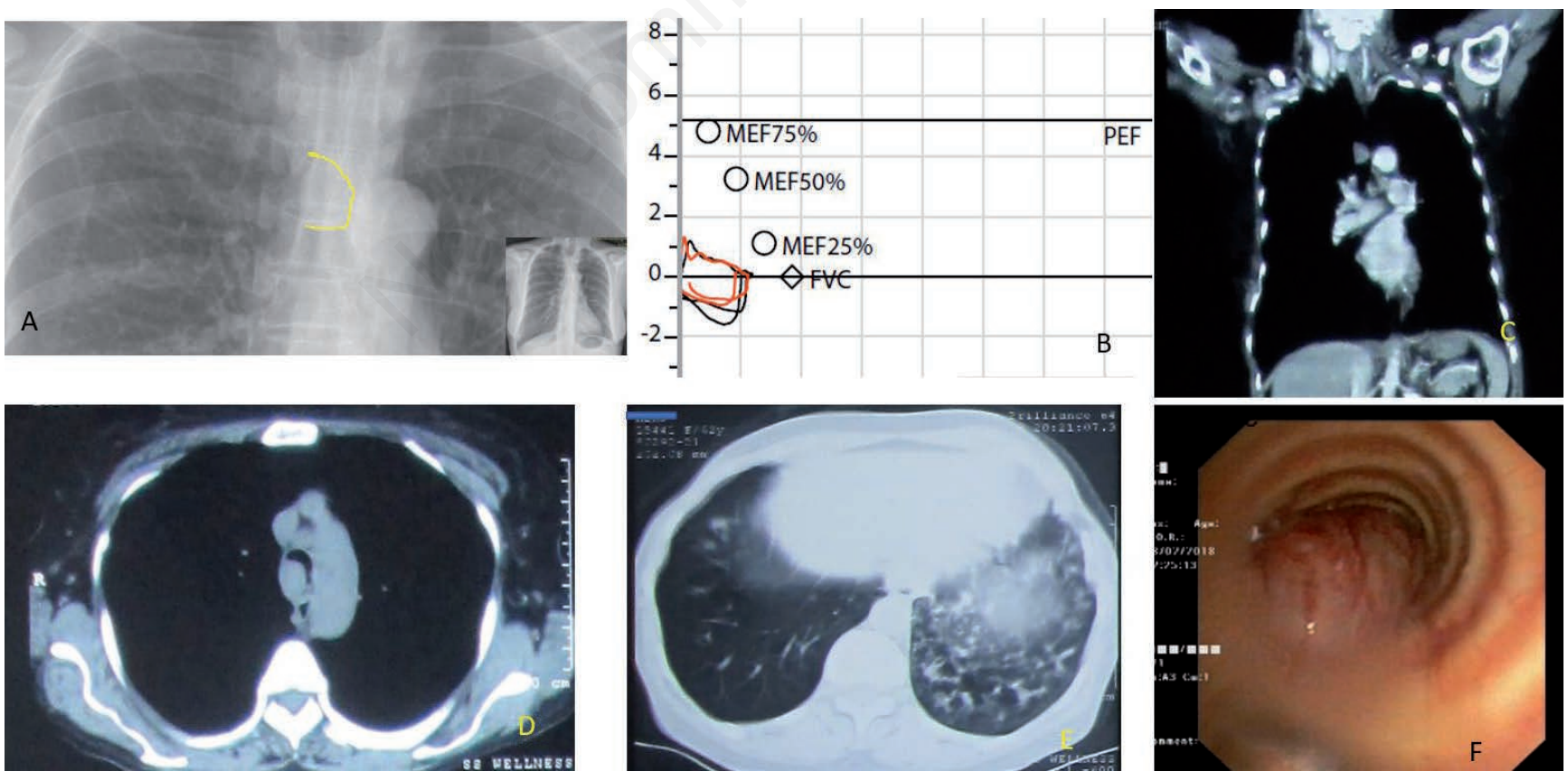

Figure 1. a) Zoom out image of chest radiograph showing tracheal mass (marked in yellow outline) arising from right tracheal wall occluding the lumen. b) Spirometry showing flattening of expiratory limb suggestive of intrathoracic obstruction. c) Coronal section of chest tomogram showing tracheal mass in lower one third of trachea d) Axial section showing tracheal mass causing more than $70 \%$ obstruction. e) Lung window showing tree-in-bud appearance and GGO. f) Bronchoscopic image showing tracheal mass causing almost complete obstruction of the tracheal lumen. 


\section{Discussion}

Intratumoral chemotherapy was first used by Bateman et al. in 1958 where it was used in breast carcinoma with 66\% improvement rate. It has been used over the years for lid carcinoma, head and neck carcinoma, skin carcinoma and deep seated intra-abdominal tumour with variable success [4].

BITC has been used in past in lung cancer but has not gain much popularity. Following table summarizes systematic review of ITC in lung cancer, where extensive literature search was done, resulted in 24 studies out of which 13 results were excluded as 4 were not in English, 4 were reports about metastasis of lung tumours in different parts of body and were not about intra-lesional chemotherapy, 3 were intertumoral chemotherapy during thoracic surgery while other 3 were review articles (Table 1).

BITC appears to be effective modality in non-emergent central airway obstruction for palliation. It results in higher concentration

Table 1. Systematic review of bronchoscopic intratumoral chemotherapy (BITC).

\begin{tabular}{|c|c|c|c|c|c|}
\hline S No & Author (year) & Clinical presentation & Protocol & Response & Complication \\
\hline 1 & Matthay et al. [6] (1986) & $\begin{array}{l}\text { Potentially resectable } \\
\text { non-small cell carcinoma } \\
\text { of the lung }\end{array}$ & $\begin{array}{l}\text { ICT using flexible fine needle } \\
\text { through the bronchoscope. } \\
\text { Peripherally located lesions, } \\
\text { not visible through it, were } \\
\text { entered with fluoroscopic } \\
\text { guidance. Agent used BCG }\end{array}$ & $\begin{array}{l}\text { No response. } \\
\text { Not lengthen disease-free } \\
\text { interval or prolong survival } \\
\text { in patients with non-small } \\
\text { cell lung cancer }\end{array}$ & Malaise fever \\
\hline 2 & Celikoglu et al. [7] (1997) & $\begin{array}{l}93 \text { patients with } \\
\text { endobronchial obstruction }\end{array}$ & $\begin{array}{l}\text { 1-3 ml each of } 50 \mathrm{mg} / \mathrm{ml} \\
5 \text {-fluorouracil, } 1 \mathrm{mg} / \mathrm{ml} \\
\text { mitomycin, } 5 \mathrm{mg} / \mathrm{ml} \\
\text { methotrexate, } 10 \mathrm{mg} / \mathrm{ml} \\
\text { bleomycin and } 2 \mathrm{mg} / \mathrm{ml} \\
\text { mitoxantrone. } \\
\text { In each session } \\
\text { bronchoscopically with } \\
\text { direct intratumoral } \\
\text { injection was performed } \\
\text { with a flexible needle }\end{array}$ & $\begin{array}{l}81 \text { of the } 93 \text { patients. } \\
\text { Endoscopically visible } \\
\text { tumours were reduced } \\
\text { in size, and infiltrative } \\
\text { changes were also } \\
\text { improved }\end{array}$ & $\begin{array}{l}8 \text { patients had febrile } \\
\text { episodes }\end{array}$ \\
\hline 3 & Weill et al. [8] (2000) & $\begin{array}{l}12 \text { patients with } \\
\text { endobronchial mass } \\
\text { ( } 6 \text { adenocarcinomas } \\
6 \text { squamous cell ca) } \\
\text { All patients' tumour contained }\end{array}$ & $\begin{array}{l}\text { Adp53 (dose range, } 1 \text { x } 10(6) \\
\text { to } 1 \text { x } 10(11) \text { plaque-forming } \\
\text { units) was administered by } \\
\text { bronchoscopic intratumoral } \\
\text { injection once every } 28 \text { days. }\end{array}$ & $\begin{array}{l}\text { Six of the } 12 \text { patients had } \\
\text { significant improvement } \\
\text { in airway obstruction, and } \\
3 \text { patients met the criteria } \\
\text { for partial response }\end{array}$ & No complications \\
\hline
\end{tabular}

4 Celikoglu et al. [4] (2006) 17 patients of NSCLC preoperatively
$6 \quad$ Jabbardarjani et al. [10] (2007)
100 patients with unresectable $20 \mathrm{ml}$ cisplatin with the lung cancer and endobronchial lesion
Direct injection of a maximum dose of $40 \mathrm{mg}$ cisplatin in aqueous solution $(4 \mathrm{mg} / \mathrm{ml})$ into the tumour through a flexible bronchoscope; administered four times: once a week during a 3-week period necrotic tumour debris was removed by piecemeal resection with forceps and suction at each session

Ad5CMV-p53 (ADVEXIN) was injected directly into the primary tumour, either endobronchially using a bronchoscope or percutaneously under computed tomography (CT) guidance concentration of $50 \mathrm{mg} / 100 \mathrm{ml}$ was injected into the bulk of the tumour through the special needle. The procedure was performed weekly for 4 sessions
1 patient had a partial Transient fever

response (squamous cell carcinoma at the carina), 10 patients had stable disease, with three lasting at least 9 months, and two patients had progressive disease

The lumen was considerably opened (more than 25\%) in 80 patients tachycardia (35) hypertensive crisis (3), and pain (27)
No major complications 
of chemotherapeutic agent in the tumour without or with very minimal systemic side effects. Conventional treatment using systemic chemotherapy and/or radiotherapy has proven unsatisfactory in yielding rapid restoration of airway patency in patients with malignant airway obstruction. Various successful palliative modalities use systemic treatment with combined local interventional modalities. In our case presence of tuberculosis delayed systemic chemotherapy but BITC can be used in such cases. After BITC, the concentration of anti-neoplastic agent decreases exponentially when it traverses through tumour vessels, and the drug concentration becomes half in 40 micrometres [15]. Intralymphnodal instillation of chemotherapy has been also shown useful in reducing tumour mass but it was not used as nodes were very small.

Our is the first case where EUS-B approach was used to instil chemotherapy. It had many advantages like patient's airway which was already compromised was not shared and throughout the procedure patient had no episode of hypoxia. As it was a vascular tumour there was anticipated danger of bleeding in airway leading to asphyxia. This danger was averted as tumour was approached via oesophagus. Few studies showed post procedural pneumonia after BITC because of aspiration of chemotherapeutic agent. It too was taken care of as puncture was made through oesophageal wall so any spill of chemotherapeutic agent in lungs was averted.

There are few limitations which are responsible for BITC not gaining much popularity, first there are no larger trials to determine its efficacy and safety profile. BITC takes longer time to palliate $\mathrm{CAO}$ when compared to rigid bronchoscopic coring and thermal endobronchial ablative measures. Expertise and evidence have remained the major issue. Most interventional pulmonologist are not comfortable with multiple sessions and theoretical complications, though practically only few developed pneumonias and rarely one required hospitalization.

\section{Conclusions}

BITC can be considered as an alternative neoadjuvant therapy to mechanical or thermal debulking for palliative management of centrally obstructing tumours, where tumour mass is easily accessible by bronchoscope with opportunity for direct intralesional injection of chemotherapeutic agent. Mechanical debulking and thermal modalities often unreachable in distal tumours or may have contraindications; bronchoscopic intralesional chemotherapy could provide an advantage over these modalities in such cases. It is safe, simple, cost-effective procedure which exhibited neither systemic toxicity nor any significant complications in expert hands. It can be done via regular flexible bronchoscopy or EBUS scope. Though further studies are needed to confirm these findings.

Table 1. Continued from previous page.

$\begin{array}{lllll}\text { S No } \text { Author (year) } & \text { Clinical presentation } & \text { Protocol } & \text { Response } & \text { Complication } \\ 7 & \text { Hohenforst-Schmidt } & \text { Five patients' stage IIIa-IV, } & \text { EBUS-needle [EBUS- } & \text { More than a 50\% reduction, } \\ \text { et al. [11] (2013) } & \text { performance status 2 (PS2) } & \begin{array}{l}\text { transbronchial needle dosing } \\ \text { (TBND)] is aiming at six }\end{array} & \text { for a massive tumour mass } \\ & & \begin{array}{l}\text { passes per lymph node to } \\ \text { optimize the permeation of }\end{array} & \\ & & & \end{array}$

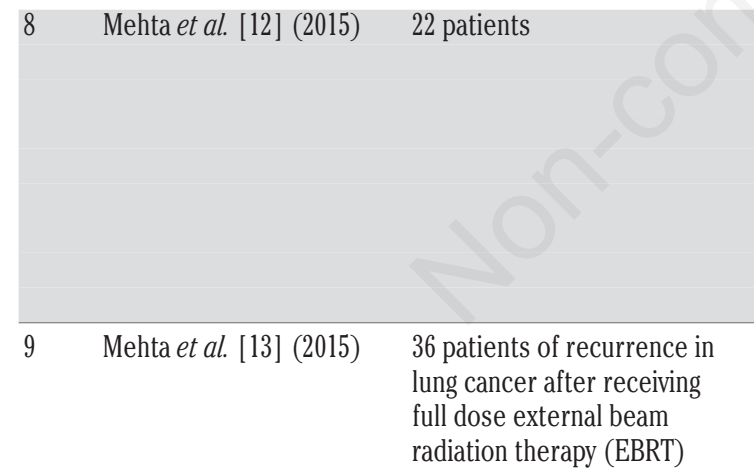

$10 \quad$ Li S-Y et al. [14] (2016) $\quad \begin{aligned} & \text { Ninety patients with } \\ & \text { NSCLC-SAO }\end{aligned}$ 

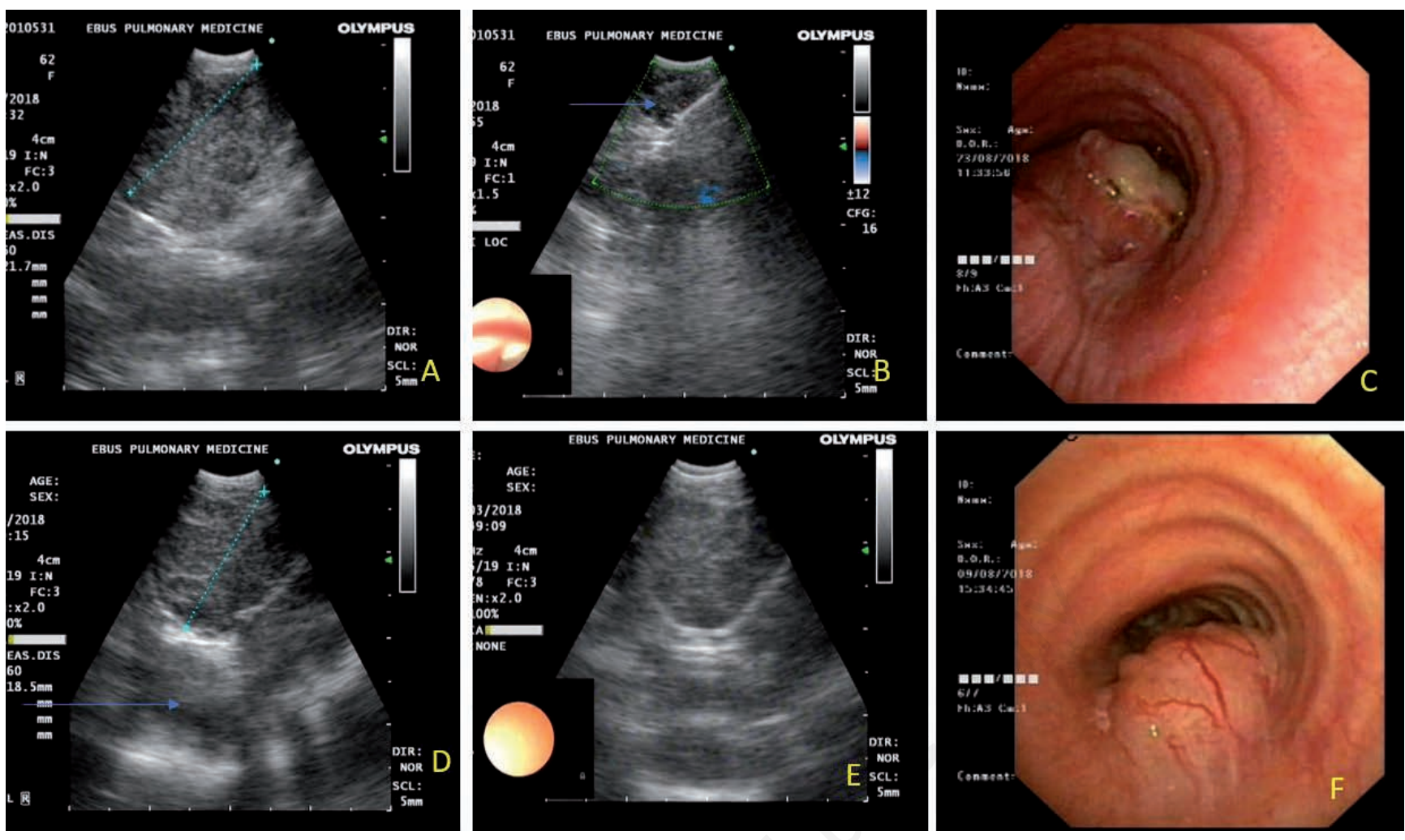

Figure 2. a) EUS-B image showing tracheal mass of size $22 \mathrm{~mm}$. b) EUS image showing instillation of aqueous cisplatin (4 mg/ml), blue arrow showing pocket of cisplatin. Mass pierced at three places and in first session $10 \mathrm{ml}$, i.e. $40 \mathrm{mg}$ cisplatin instilled intra lesionally c) Bronchoscopic image after $1^{\text {st }}$ week showed shrinkage of mass with symptomatic relief. d) EUS-B image showed clear increase in airway indicated by blue arrow and decrease in size of mass. e) After $4^{\text {th }}$ session mass shrunk further and airway cross-sectional area increased. $f$ ) Bronchoscopic image after 1 week of $4^{\text {th }}$ session of intra lesional instillation.

\section{References}

1. Ernst A, Feller-Kopman D, Becker HD, Mehta AC. Central airway obstruction. Am J Respir Crit Care Med 2004;169:1278-97.

2. Diaz-Mendoza J, Peralta A, Debiane L, Simoff M. Rigid bronchoscopy. Semin Respir Crit Care Med 2018;39:674-84.

3. Steinfort DP, Farmer MW, Irving LB, et al. Pulmonologist-performed per-esophageal needle aspiration of parenchymal lung lesions using an EBUS bronchoscope: diagnostic utility and safety. J Bronchology Interv Pulmonol 2017;24:117-24

4. Oliveira CM, Colaiácovo R, Araki O, et al. The role of endoscopic ultrasound in the staging of tracheal neoplasm: a brief review. Rev Assoco Med Bras (1992) 2019;65:589-91.

5. Celikoglu SI, Celikoglu F, Goldberg EP. Endobronchial intratumoral chemotherapy (EITC) followed by surgery in early nonsmall cell lung cancer with polypoid growth causing erroneous impression of advanced disease. Lung Cancer 2006;54:339-46.

6. Matthay RA, Mahler DA, Beck GJ, et al. Intratumoral Bacillus Calmette-Guerin immunotherapy prior to surgery for carcinoma of the lung: results of a prospective randomized trial. Cancer Res 1986;46:5963-8.

7. Celikoğlu SI, Karayel T, Demirci S, et al. Direct injection of anti-cancer drugs into endobronchial tumours for palliation of major airway obstruction. Postgrad Med J 1997;73:159-62.

8. Weill D, Mack M, Roth J, et al. Adenoviral-mediated p53 gene transfer to non-small cell lung cancer through endobronchial injection. Chest 2000;118:966-70.
9. Fujiwara T, Tanaka N, Kanazawa S, et al. Multicenter phase I study of repeated intratumoral delivery of adenoviral p53 in patients with advanced non-small-cell lung cancer. J Clin Oncol 2006;24:1689-99.

10. Jabbardarjani H, Safara H, Kharabian S, Reza M. Endobronchial chemotherapy in malignant airway lesions of the lung: Report of 3 years experience. J Bronchology 2007;14:242-5

11. Hohenforst-Schmidt W, Zarogoulidis P, Darwiche K, et al. Intratumoral chemotherapy for lung cancer: re-challenge current targeted therapies. Drug Des Devel Ther 2013;7:571-83.

12. Mehta HJ, Begnaud A, Penley AM, et al. Restoration of patency to central airways occluded by malignant endobronchial tumors using intratumoral injection of cisplatin. Ann Am Thorac Soc 2015;12:1345-50.

13. Mehta HJ, Begnaud A, Penley AM, et al. Treatment of isolated mediastinal and hilar recurrence of lung cancer with bronchoscopic endobronchial ultrasound guided intratumoral injection of chemotherapy with cisplatin. Lung Cancer 2015;90:542-7.

14. Li SY, Li Q, Guan WJ, et al. Effects of para-toluenesulfonamide intratumoral injection on non-small cell lung carcinoma with severe central airway obstruction: A multi-center, nonrandomized, single-arm, open-label trial. Lung Cancer 2016;98:43-50.

15. Li X, Liu X, Rao X, et al. A case report of local treatment of inoperable squamous cell lung carcinoma with convex-probe endobronchial ultrasound-guided intratumoral injection of cisplatin in a patient with severe COPD. Med (Baltimore) 2017;96:e7070. 